\title{
Superhydrophobic photocatalytic PTFE - titania coatings deposited by reactive pDC magnetron sputtering from a blended powder target
}

\author{
Marina Ratova ${ }^{1 *}$, Peter J. Kelly ${ }^{1}$, Glen T. West ${ }^{1}$ \\ ${ }^{1}$ Surface Engineering Group, Manchester Metropolitan University, Manchester, M1 5GD \\ * Corresponding author: M Ratova, School of Engineering, Manchester Metropolitan University, John \\ Dalton Building, Chester Street, Manchester M1 5GD, UK, tel. +44 161247 4648, e-mail address \\ marina_ratova@hotmail.com
}

\begin{abstract}
The production of photocatalytic coatings with superhydrophobic properties, as opposed to the conventional hydrophilic properties, is desirable for the prevention of adhesion of contaminants to photocatalytic surfaces with subsequent deterioration of photocatalytic properties. In this work polytetrafluoroethylene (PTFE) - $\mathrm{TiO}_{2}$ composite thin films were deposited using a novel method of reactive pulsed direct current $(\mathrm{pDC})$ magnetron sputtering of a blended PTFE - titanium oxide powder target. The surface characteristics and photocatalytic properties of the deposited composite coatings were studied. The as-deposited coatings were annealed at $523 \mathrm{~K}$ in air and analysed with Raman spectroscopy, optical profilometry and scanning electron microscopy. Hydrophobicity was assessed though measurements of water contact angles, and photocatalytic properties were studied via methylene blue dye degradation under UV irradiation. It was found that variations of gas flow and, hence, process pressures allowed deposition of samples combining superhydrophobicity with stable photocatalytic efficiency under UV light irradiation. Reversible wettability behaviour was observed with the alternation of light-dark cycles.
\end{abstract}

\section{Introduction}

Photocatalytic surfaces have gained increasing popularity over the past few decades. Since their discovery in 1969 by Fujishima and Honda [1], photocatalytic materials are used as a sustainable approach to air and water purification, water splitting and decontamination and disinfection of surfaces [2-4]. Superhydrophilicity is one of the widely reported features of titania-based photocatalytic surfaces [5]. Low contact angles (below 10 degrees) can be seen when a droplet of water is placed onto an irradiated photocatalytic surface. However, superhydrophobic surfaces are often more desirable for environmental cleaning than superhydrophilic ones, as they prevent adhesion of contaminants and microorganisms to the surface $[6,7]$, and therefore have an antifouling effect that helps to prevent the deterioration of photocatalytic properties. Superhydrophobic surfaces are characterised with low surface energy and high water contact angles (over $150^{\circ}$ ). Superhydrophobicity is typically described as resulting from nano- and micro-scale roughness in combination with the hydrophobic functionality of the material [8].

While most studies are focused on the superhydrophilic properties of photocatalytic surfaces, there is a very limited number of works dealing with superhydrophobic photocatalysts. Only a few attempts to produce materials that combine superhydrophobicity with photocatalytic activity have been reported to date. Typically coatings combining photocatalytic and superhydrophobic properties are produced using chemical methods, such as hydrothermal $[9,10]$, liquid phase deposition [11], sol-gel [12], etc. A chemical vapour deposition (CVD) method was used by Crick et al. for preparation of a polymer matrix with incorporated titania particles [13]. Superhydrophobic composite materials were prepared by Kamegawa and co-workers $[14,15]$ using RF magnetron co-sputtering of $\mathrm{TiO}_{2}$ and PTFE targets. Several studies use photocatalytic materials other than $\mathrm{TiO}_{2}$, such as $\mathrm{ZnO}$ and $\mathrm{Bi}_{2} \mathrm{WO}_{6}$, 
for preparation of superhydrophobic surfaces $[16,17]$. It is clear that combining superhydrophobicity with considerable photocatalytic activity is a rather challenging task in $\mathrm{TiO}_{2}$ based materials, as titanium dioxide surfaces typically exhibit hydrophilic properties, turning into superhydrophilic upon ultraviolet (UV) light exposure.

Magnetron sputtering is a well-known method for thin film deposition $[18,19]$, including titanium dioxide and modified titanium dioxide photocatalytic coatings [4, 20-22]. Deposition of coatings by mid-frequency pulsed DC magnetron sputtering enables control of coating chemical composition and thickness. Compared to traditional chemical methods of coating fabrication, such as sol-gel and dip-coating, it offers more freedom in selecting and adjusting deposition conditions [23], as well as the opportunity to scale up, if required. Compared to an RF sputtering system, power supplies for pulsed DC sputtering are relatively inexpensive and, as they do not require tuning circuits, are straightforward to use, making the process feasible on both laboratory and industrial scale [18]. However, there are some limitations in the use of pulsed DC magnetron sputtering for thin film deposition. Thus, unlike the sputter targets used in RF magnetron sputtering, the target generally requires significant conductivity, therefore the choice of materials to be sputtered is limited. However, the use of loosely packed (not sintered) blended powder targets helps to overcome materials limitations and enables simple control of coating composition by varying the ratio of materials in the powder target [24-27]. This method has been reported to produce photocatalytic coatings with the activities similar to the ones produced by conventional sputtering techniques [28].

In this work a reactive pulsed DC magnetron sputtering technique from a blended PTFE $-\mathrm{Ti}_{2} \mathrm{O}_{3}$ powder target was employed for the production of photocatalytic superhydrophobic coatings, reportedly for the first time. The main aim of the study was to evaluate the suitability of sputtering the powder target as a production method for superhydrophobic photocatalytic coatings.

\section{Experimental}

\subsection{Deposition}

In a series of experiments, PTFE-titanium dioxide composite coatings were deposited by reactive pulsed direct current ( $\mathrm{pDC}$ ) magnetron sputtering from a blended powder targets in a purpose-built sputtering rig equipped with a $180 \mathrm{~mm}$ diameter unbalanced magnetron. The target was composed from 14 grams of PTFE ( $\leq 35 \mu \mathrm{m}$ particle size), which was blended with 4 grams of $\mathrm{Ti}_{2} \mathrm{O}_{3}(\leq 150 \mu \mathrm{m}$ particle size) (titanium (III) oxide was used because of its high electrical conductivity [29], compared to $\mathrm{TiO}_{2}$, in order to facilitate sputtering). All reagents were purchased from Sigma-Aldrich. The powder mixture was spread across the surface of a copper backing plate recessed to a depth of 2 $\mathrm{mm}$, and then lightly tamped down to provide uniform coverage of the backing plate. No further processes were employed to form the target. The magnetron was driven in a pulsed sputtering mode using an Advanced Energy Pinnacle Plus power supply; a pulse frequency of $350 \mathrm{kHz}$ and a duty of $50 \%$ were used for all deposition runs. The power supply was operated in power regulation mode at 200W. The deposition time was $30 \mathrm{~min}$ for all the coatings. The sputtering process was carried out in an argon / oxygen atmosphere at a pressure of 0.16-0.33 Pa. The gas flows were controlled with mass-flow controllers; the Ar flow was varied from 7.5 to $15 \mathrm{sccm}$, the oxygen flow was varied from 1 to $3 \mathrm{sccm}$. The oxygen was added to the runs to compensate for the oxygen deficiency of the $\mathrm{Ti}_{2} \mathrm{O}_{3}$ powder and, thereby, produce stoichiometric $\mathrm{TiO}_{2}$ coatings. The substrates were $35 \times 35 \mathrm{~mm} 304$ 2B polished stainless steel coupons, which were ultrasonically pre-cleaned in propanol and placed onto the electrically floating substrate holder. The distance between the target and substrate holder was $10 \mathrm{~cm}$. Additionally, titania coatings were deposited for comparison purposes from a target composed of $10 \mathrm{~g}$ of $\mathrm{Ti}_{2} \mathrm{O}_{3}$ only. 
To promote crystallisation of the coatings, they were annealed in air at $523 \mathrm{~K}$ for $30 \mathrm{~min}$ and then allowed to cool gradually for $2 \mathrm{~h}$ to avoid thermal stresses in the coatings.

\subsection{Coating characterisation}

Crystallographic information of the coatings was obtained with Raman spectroscopy (Renishaw Invia, $514 \mathrm{~mm}$ laser). Coatings thickness was measured with a Dektak surface profilometer. Surface roughness of the coatings was assessed with a Zemetrics 3D optical profilometer. Further information about surface morphology was obtained using a scanning electron microscope (SEM) (Zeiss Supra 40). Static water contact angles (WCA) were measured with a Theta Lite optical tensiometer. The average contact angles values were obtained by taking a mean value of 5 measurements across the sample surface.

\subsection{Evaluation of photocatalytic activity}

The photocatalytic properties of the coatings were assessed using the methylene blue (MB) degradation test under a UV light source ( $2 \times 15$ W $352 \mathrm{~nm}$ Sankyo Denki BLB lamps). The MB aqueous solution (concentration $1.5 \mu \mathrm{mol} / \mathrm{l}$ ) absorbance peak at $665 \mathrm{~nm}$ was monitored in continuous mode for 60 min using an Ocean Optics USB 4000 spectrometer. The first order linear relationship was revealed by plotting $\ln \left(A_{t=0} / A_{t}\right)$ as a function of irradiation time, where $A_{t=0}$ is absorption value at time $0, A_{t}$ is absorption value at the time of experiment. Prior to the degradation test, samples were immersed into the MB solution for a total time of $30 \mathrm{~min}$ in the dark to reach the adsorption-desorption equilibrium. A full description of the experimental details and emission spectrum of the UV light tubes used for the experiment are given elsewhere [30, 31]. A series of reference tests was carried out prior to the photocatalytic activity measurements, including testing under the UV light irradiation with a blank sample (uncoated stainless steel), as well as testing of each sample under dark conditions to prove that the solution decolourisation was caused by photodecomposition of the dyes, rather than any side reactions. Additionally, photocatalytic reusability and the photostability of the hydrophobicity of the samples under UV light irradiation was tested. For the latter one hour irradiation cycles with the UV light source (identical to that described earlier) were alternated with 1-hour darkness cycles; and the water contact angles were recorded at the end of each cycle.

\section{Results and discussion}

\subsection{Coatings overview and Raman spectroscopy}

An overview of the deposited coatings is given in Table 1. Results of Raman spectroscopy showed that all as-deposited coatings were amorphous; therefore, they were annealed at $523 \mathrm{~K}$ for the development of crystal structure. The thickness of the coatings was estimated by means of surface profilometry and later confirmed with the use of 3D optical profilometry. The thickness of the composite coatings varied from 70 to $110 \mathrm{~nm}$, depending on deposition conditions, with coatings PT3 and PT4, deposited at higher working pressures, being slightly thicker. The titania coating was thinner, with the estimated thickness of $50 \mathrm{~nm}$.

The results of Raman spectroscopy of the annealed coatings showed that all coatings were in the anatase titania phase, with characteristic Raman bands observed at 144, 397, 516 and $638 \mathrm{~cm}^{-1}$. No additional peaks that could be attributed to the presence PTFE were found for any of the samples studied and no other titania phases were observed [32]. Examples of Raman spectroscopy results for the titania coating compared to a PTFE - $\mathrm{TiO}_{2}$ composite coating (sample PT3) are shown in the Figure 1. It is obvious from the data presented that the Raman peaks of the composite coating were 
of lower intensity, compared to titania indicating that the latter sample had a greater degree of crystallinity than the composite one.

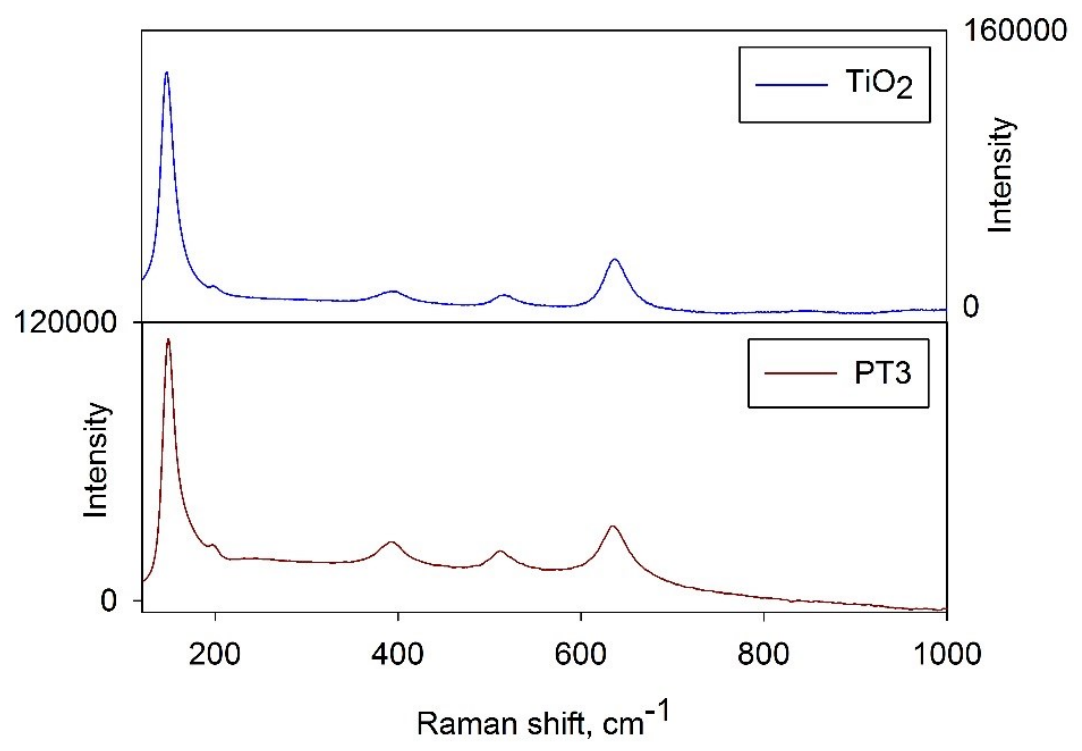

Figure 1. Results of Raman spectroscopy for titania and PTFE-TiO 2 (PT3) coatings after annealing at $523 \mathrm{~K}$

Table 1. Overview of deposition conditions and properties of the coatings

\begin{tabular}{|l|l|l|l|l|l|l|l|l|}
\hline $\begin{array}{l}\text { Coating } \\
\text { ID }\end{array}$ & $\begin{array}{l}\text { Ar } \\
\text { flow, } \\
\text { scc } \\
\mathrm{m}\end{array}$ & $\begin{array}{l}\text { Oxyge } \\
\mathrm{nflow}, \\
\mathrm{sccm}\end{array}$ & $\begin{array}{l}\text { Ar/O } \\
\text { ratio in } \\
\text { gas } \\
\text { mixture }\end{array}$ & $\begin{array}{l}\text { Depositio } \\
\mathrm{n} \\
\text { pressure, } \\
\mathrm{Pa}\end{array}$ & $\begin{array}{l}\text { Estimate } \\
\text { d coating } \\
\text { thickness, } \\
\mathrm{nm}\end{array}$ & $\begin{array}{l}\text { Surface } \\
\text { roughness } \\
\mathrm{nm}\end{array}$ & $\begin{array}{l}\text { Water } \\
\text { contac } \\
\text { t angle, } \\
\text { deg. }\end{array}$ & $\begin{array}{l}\text { Methylen } \\
\text { e blue } \mathrm{k}_{\mathrm{a}} \times \\
10^{-5}, \mathrm{~s}^{-1}\end{array}$ \\
\hline PT1 & 7.5 & 1 & $88 / 12$ & 0.16 & 70 & 93 & 86 & 5.1 \\
\hline PT2 & 7.5 & 3 & $71 / 29$ & 0.18 & 80 & 188 & 120 & 6.9 \\
\hline PT3 & 15 & 1 & $94 / 6$ & 0.3 & 110 & 238 & 152 & 5.1 \\
\hline PT4 & 15 & 3 & $83 / 17$ & 0.33 & 110 & 240 & 141 & 4.3 \\
\hline $\mathrm{TiO}_{2}$ & 15 & 3 & $83 / 17$ & 0.33 & 50 & 22 & 31 & 2.5 \\
\hline $\begin{array}{l}\text { Stainless } \\
\text { steel }\end{array}$ & - & - & - & - & - & 18 & 92 & 0 \\
\hline
\end{tabular}

\subsection{Scanning electron microscopy}

SEM images showing the surface topography of stainless steel coupons coated with PTFE - $\mathrm{TiO}_{2}$ composite coatings grown at various gas flows are shown in the Figure 2 a-d. The corresponding images of water droplets on the surfaces are given in the inserts. SEM image 2e shows the surface of the titania coating, and the surface of uncoated stainless steel coupon is given in the image $2 \mathrm{f}$. It is obvious from the SEM images that coatings deposited at different argon pressures were characterised with distinctively different surface topographies. Thus, the coating deposited at the lowest process pressure ( $7.5 \mathrm{sccm}$ of $\mathrm{Ar}$ and $1 \mathrm{sccm}$ of $\mathrm{O}_{2}$ ) (Figure 2a) is characterised with a relatively rough surface replicating the underlying substrate, without well-defined features. As the oxygen flow was increased to $3 \mathrm{sccm}$ and the process pressure raised to $0.18 \mathrm{~Pa}$, larger spherical surface features can be seen on the image, with average sizes of $550 \mathrm{~nm}$ for the bigger clusters and 
$100 \mathrm{~nm}$ for the smaller ones. Further increases of the deposition pressure resulted in the gas phase scattering and filling in the surface features and therefore formation of visibly smoother subsurfaces (Figures $2 \mathrm{c}$ and $2 \mathrm{~d}$ ) with spherically-shaped clusters of various sizes, ranging from 70 to 600 $\mathrm{nm}$. As the oxygen flow was increased to $3 \mathrm{sccm}$ with the Ar flow kept as $15 \mathrm{sccm}$, and the deposition pressure at $0.33 \mathrm{~Pa}$, the clusters on the surface became more uniform in size, ranging from 150 to $500 \mathrm{~nm}$. As for titania coating, it is obvious that it is relatively flat compared to composite films, fully replicates the surface pattern of the underlying stainless steel substrate and does not have surfaces features which therefore can be without doubts attributed to presence of PTFE in coatings.

\subsection{Contact angle measurements}

The wettability of the composite coatings was evaluated using WCA measurements (static CA without surfaces pre-irradiation). The mean values of the measured WCAs are given in the table 1. The uncoated stainless steel showed a contact angle of $92^{\circ}$, therefore the substrate used for deposition did not have superhydrophobic properties on its own. Sample PT1 showed a WCA similar to that of the uncoated substrate. As the size of the clusters on the surface of the coating increased the surface became more hydrophobic, with a WCA of $120^{\circ}$ for sample PT2 and $152^{\circ}$ for sample PT3. However further increase in cluster sizes resulted in decrease of distribution density and drop of WCA to $141^{\circ}$ for PT4. It is well-known that superhydrophobicity can only be achieved with the right combination of surface roughness and hydrophobic functionality [8]. Therefore, it can be suggested that the superhydrophobicity here is achieved through the combination of surface roughness (polished stainless steel in combination with the surface clusters of the material) and the hydrophobic functionality of PTFE introduced to the coating. The titania coating exhibited a relatively low contact angle of $31^{\circ}$, which is in good accordance with literature information on wettability of titanium dioxide without surface pre-irradiation [33, 34]. 

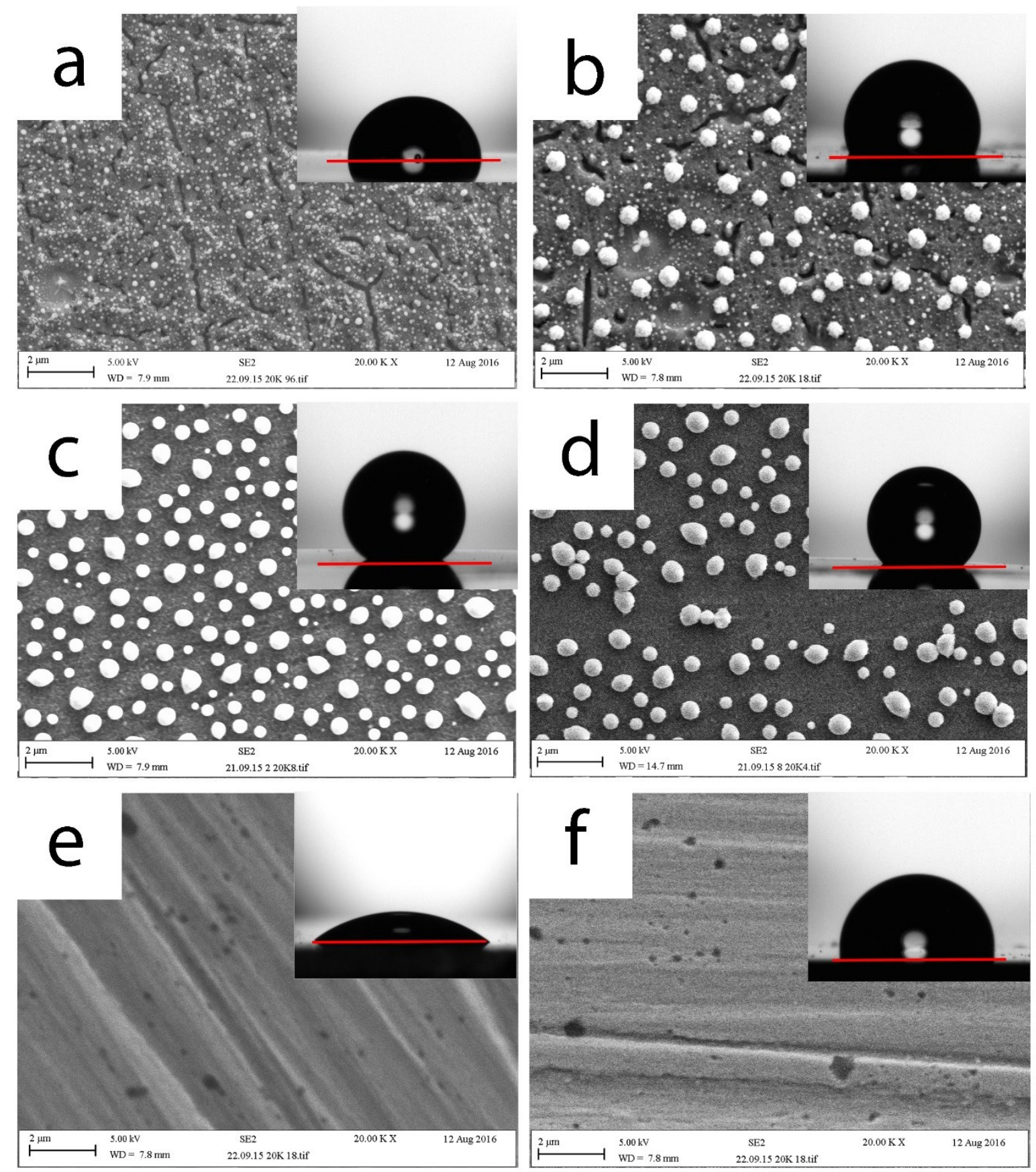

Figure 2. SEM images of $\mathrm{TiO}_{2}$ - PTFE composite materials after annealing at 523K; a) sample PT1, b) sample PT2, c) sample PT3, d) sample PT4, e) $\mathrm{TiO}_{2}$ coating, f) uncoated stainless steel. Inserts on the images show water droplets on the surface of the corresponding samples.

\subsection{Photocatalytic activity}

The photocatalytic activity of the coatings was evaluated by monitoring the decomposition of MB for 1 hour under UV irradiation; the results are presented in the Figure 3. No noticeable reduction of the MB absorbance peak could be seen in the dark experiments; hence these results are not presented in the figure. The quantitative values of the degradation reaction constants are given in the table 1. Of the coatings studied the highest photocatalytic activity was seen for sample PT2, most likely due to combination of high surface roughness and lower hydrophobicity resulting in better contact of MB with surface. Samples PT1, PT3 and PT4 showed very similar rates of dye degradation. Compared to the titania sample, the composite coatings demonstrated 1.7-2.7 times higher photocatalytic 
activity, however it should be noted that surface roughness of PTFE - $\mathrm{TiO}_{2}$ samples was almost 10 times higher, therefore the composite samples provided higher contact areas with the pollutant. As the MB degradation reaction rate constants of the composite coatings were only about 2 times higher compared to titania, this suggests that the surface features observed on the composite samples are predominantly PTFE-based, and therefore their increased surface area does not make a significant contribution to the observed increase in photocatalytic activity for these coatings.

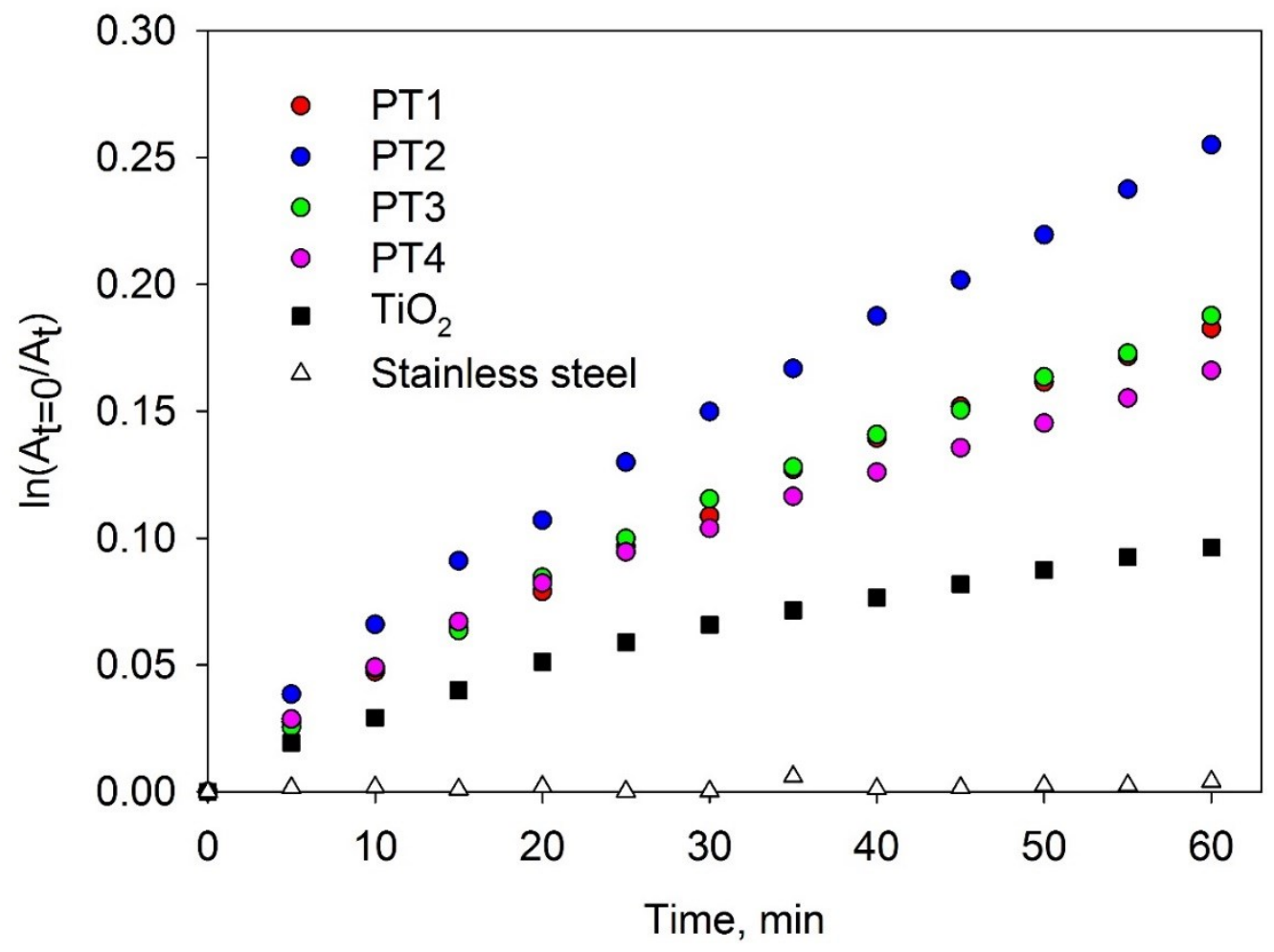

Figure 3. Methylene blue degradation kinetics in contact with PTFE-TiO ${ }_{2}$ composite coatings and uncoated stainless steel

\subsection{Stability of photocatalytic and superhydrophobic properties}

It is often mentioned that the combination of photocatalytic and superhydrophobic properties in one material often results in the quick decomposition of the material itself, thus ceasing the superhydrophobicity irreversibly [35]. Therefore, additional tests aimed at the evaluation of the reusability of the composite materials were carried out. Coating PT3, as the most hydrophobic of the array, was selected for the reusability tests. Thus, the MB photodegradation test was repeated 5 times using the same sample. The results of these tests are depicted in Figure 4a. As can be seen, there was no significant photoactivity loss after 5 repeat cycles, indicating that the coating exhibited satisfactory reusability after 5 cycles of photodegradation testing. 

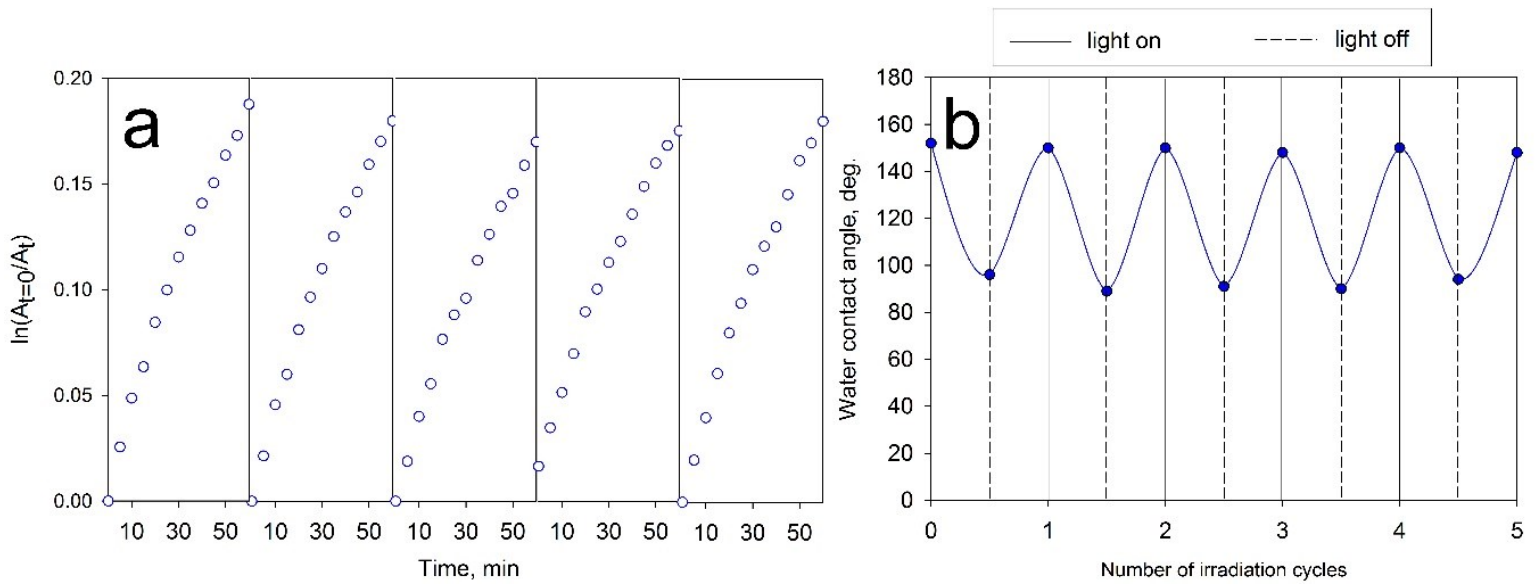

Figure 4. Repeated experiments: a) degradation kinetics of methylene blue during 5 cycles of dye photodegradation using sample PT3; b) water droplet contact angle changes on the surface of sample PT3 in 5 cycles of UV irradiation / darkness

The photostability of the hydrophobicity of sample PT3 was further investigated. The results are illustrated in Figure 4b. The sample surface was dried with compressed air between light and dark cycles. It can be seen that this coating exhibited a stable pattern of reversible wettability, with CA of about $95^{\circ}$ after 1 hour UV irradiation. However, as the UV irradiation stops, the surface returns to its superhydrophobic state with CA over $150^{\circ}$. The photoinduced hydrophilicity of titanium dioxide is typically explained by formation of $\mathrm{Ti}-\mathrm{O}-\mathrm{H}$ bonds. In a composite material, as described here, the reversible wettability phenomenon can be explained as arsing because the photoinduced hydrophilicity of $\mathrm{TiO}_{2}$ is partially terminated by hydrophobic entities, hence the contact angles upon UV light exposure do not drop lower than ca. $95^{\circ}$. Though it is expected that photocatalytic degradation of these hydrophobic entities may occur over the time, 5 repeat cycles of UV irradiation / darkness did not result in a noticeable reduction of superhydrophobicity.

\section{Conclusion}

A superhydrophobic composite material was successfully deposited using pulsed DC magnetron sputtering from a blended powder target onto polished stainless steel coupons. The blended target was formed from PTFE and $\mathrm{Ti}_{2} \mathrm{O}_{3}$ powders. After annealing in air at $523 \mathrm{~K}$ all samples exhibited anatase crystallinity. Samples deposited at higher process pressures exhibited superhydrophobic properties, with no further chemical or mechanical treatment required to achieve superhydrophobicity. It was shown that the total process pressure, as well as $\mathrm{Ar} / \mathrm{O}_{2}$ ratio in the gas mixture had a critical influence on surface texture and surface feature distribution in the deposited films. Though all the coatings deposited were characterised with relatively high photocatalytic activity compared to titania samples of the same geometrical size, the water contact angles varied significantly, with the highest static CA achieved reaching $152^{\circ}\left( \pm 2^{\circ}\right)$. In a series of repeated MB photodegradation tests there was no noticeable decrease of photocatalytic activity. Photostability tests showed a reversible wettability effect, where the surface was able to return to a superhydrophobic state after UV irradiation was paused.

Overall it has been shown that pulsed DC reactive magnetron sputter deposition from a blended target has potential as a method for the production of superhydrophobic photocatalytic coatings. However, further investigation of the influence of process parameters and the optimisation of deposition conditions is required. 


\section{References}

1. Fujishima A., H.K., Kikuchi S., Photosensitized electrolytic oxidation on semiconducting $n$-type TiO2 electrode. Kogyo Kagaku Zasshi, 1969. 72: p. 108-113.

2. Pelaez, M., et al., A review on the visible light active titanium dioxide photocatalysts for environmental applications. Applied Catalysis B: Environmental, 2012. 125(0): p. 331-349.

3. Paz, Y., Application of $\mathrm{TiO}_{2}$ photocatalysis for air treatment: Patents ${ }^{\mathrm{TM}}$ overview. Applied Catalysis B: Environmental, 2010. 99(3-4): p. 448-460.

4. Kelly, P.J., et al., Structural Formation and Photocatalytic Activity of Magnetron Sputtered Titania and Doped-Titania Coatings. Molecules, 2014. 19(10): p. 16327-16348.

5. Fujishima, A. and X. Zhang, Titanium dioxide photocatalysis: present situation and future approaches. Comptes Rendus Chimie, 2006. 9(5-6): p. 750-760.

6. Zhang, X.X., L. Wang, and E. Levanen, Superhydrophobic surfaces for the reduction of bacterial adhesion. Rsc Advances, 2013. 3(30): p. 12003-12020.

7. Nosonovsky, M. and B. Bhushan, Superhydrophobic surfaces and emerging applications: Non-adhesion, energy, green engineering. Current Opinion in Colloid \& Interface Science, 2009. 14(4): p. 270-280.

8. Lee, J.H., et al., Superhydrophobic surfaces with photocatalytic activity under UV and visible light irradiation. Catalysis Today, 2016. 260: p. 32-38.

9. Gao, L.K., et al., A robust superhydrophobic antibacterial $\mathrm{Ag}-\mathrm{TiO}_{2}$ composite film immobilized on wood substrate for photodegradation of phenol under visible-light illumination. Ceramics International, 2016. 42(2): p. 2170-2179.

10. Nishimoto, S., et al., $\mathrm{TiO}_{2}$-based superhydrophobic-superhydrophilic pattern with an extremely high wettability contrast. Thin Solid Films, 2014. 558: p. 221-226.

11. Wu, Y.P., et al., A transparent $\mathrm{CNTS} / \mathrm{TiO}_{2}$ composite film with superhydrophobic and photocatalytic functions self-assembled by liquid-phase deposition. Materials Chemistry and Physics, 2015. 149: p. 522-529.

12. Duan, Z.F., et al., A facial approach combining photosensitive sol-gel with self-assembly method to fabricate superhydrophobic $\mathrm{TiO}_{2}$ films with patterned surface structure. Applied Surface Science, 2016. 360: p. 1030-1035.

13. Crick, C.R., et al., Superhydrophobic Photocatalytic Surfaces through Direct Incorporation of Titania Nanoparticles into a Polymer Matrix by Aerosol Assisted Chemical Vapor Deposition. Advanced Materials, 2012. 24(26): p. 3505-3508.

14. Kamegawa, T., Y. Shimizu, and H. Yamashita, Superhydrophobic Surfaces with Photocatalytic Self-Cleaning Properties by Nanocomposite Coating of $\mathrm{TiO}_{2}$ and Polytetrafluoroethylene. Advanced Materials, 2012. 24(27): p. 3697-3700.

15. Kamegawa, T., K. Irikawa, and H. Yamashita, Unique Surface Properties of Nanocomposite Thin Film Photocatalysts of $\mathrm{TiO}_{2}$ and Poly(tetrafluoroethylene). Chemistry Letters, 2015. 44(4): p. 509-511.

16. Yang, C.Y., et al., One-step synthesis of $\mathrm{Bi}_{2} \mathrm{WO}_{6} / \mathrm{TiO}_{2}$ heterojunctions with enhanced photocatalytic and superhydrophobic property via hydrothermal method. Journal of Materials Science, 2016. 51(2): p. 1032-1042.

17. Ennaceri, H., et al., Water-resistant surfaces using zinc oxide structured nanorod arrays with switchable wetting property. Surface \& Coatings Technology, 2016. 299: p. 169-176.

18. Kelly, P.J. and R.D. Arnell, Magnetron sputtering: a review of recent developments and applications. Vacuum, 2000. 56(3): p. 159-172.

19. Arnell, R.D., P.J. Kelly, and J.W. Bradley, Recent developments in pulsed magnetron sputtering. Surface and Coatings Technology, 2004. 188-189(0): p. 158-163.

20. Ratova, M., et al., Enhanced properties of magnetron sputtered photocatalytic coatings via transition metal doping. Surface and Coatings Technology, 2013. 228, Supplement 1(0): p. S544-S549. 
21. Ratova, M., et al., Synergistic effect of doping with nitrogen and molybdenum on the photocatalytic properties of thin titania films. Vacuum, 2015. 114(0): p. 205-212.

22. Onifade, A.A. and P.J. Kelly, The influence of deposition parameters on the structure and properties of magnetron-sputtered titania coatings. Thin Solid Films, 2006. 494(1-2): p. 8-12.

23. Wang, H.Y., T.M. Wang, and P. Xu, Effects of substrate temperature on the microstructure and photocatalytic reactivity of TiO2 films. Journal of Materials Science-Materials in Electronics, 1998. 9(5): p. 327-330.

24. Farahani, N., et al., An Investigation into $\mathrm{W}$ or $\mathrm{Nb}$ or $\mathrm{ZnFe}_{2} \mathrm{O}_{4}$ Doped Titania Nanocomposites Deposited from Blended Powder Targets for UV/Visible Photocatalysis. Coatings, 2013. 3(3): p. 153-165.

25. Jefferson, L.U., et al., Preparation and Characterization of Polyhedral Oligomeric Silsesquioxane-Containing, Titania-Thiol-Ene Composite Photocatalytic Coatings, Emphasizing the Hydrophobic-Hydrophilic Transition. Acs Applied Materials \& Interfaces, 2015. 7(23): p. 12639-12648.

26. Audronis, M., et al., Pulsed magnetron sputtering of chromium boride films from loose powder targets. Surface \& Coatings Technology, 2006. 200(14-15): p. 4166-4173.

27. Zhou, Y. and P.J. Kelly, The properties of tin-doped indium oxide films prepared by pulsed magnetron sputtering from powder targets. Thin Solid Films, 2004. 469: p. 18-23.

28. Farahani, N., et al., Photocatalytic activity of reactively sputtered and directly sputtered titania coatings. Thin Solid Films, 2011. 520(5): p. 1464-1469.

29. Tsujimoto, Y., et al. Size dependence of structural, magnetic, and electrical properties in corundum-type $\mathrm{Ti}_{2} \mathrm{O}_{3}$ nanoparticles showing insulator-metal transition. Journal of Asian Ceramic Societies, 2015. 3, 325-333.

30. Ratova, M., et al., Deposition of Visible Light Active Photocatalytic Bismuth Molybdate Thin Films by Reactive Magnetron Sputtering. Materials, 2016. 9(2): p. 67.

31. Ratova, M., G.T. West, and P.J. Kelly, Optimisation of HiPIMS photocatalytic titania coatings for low temperature deposition. Surface and Coatings Technology, 2014. 250(0): p. 7-13.

32. Franco, L.M., et al., Photocatalytic activity of nitrogen-doped and undoped titanium dioxide sputtered thin films. Superficies y Vacío, 2012. 25(3): p. 4.

33. Lee, Y.C., et al., Photocatalysis and hydrophilicity of doped $\mathrm{TiO}_{2}$ thin films. Journal of Colloid and Interface Science, 2003. 267(1): p. 127-131.

34. Rampaul, A., et al., Titania and tungsten doped titania thin films on glass; active photocatalysts. Polyhedron, 2003. 22(1): p. 35-44.

35. Xu, Q.F., et al., Superhydrophobic TiO2-Polymer Nanocomposite Surface with UV-Induced Reversible Wettability and Self-Cleaning Properties. Acs Applied Materials \& Interfaces, 2013. 5(18): p. 8915-8924. 